\title{
LoRd Fairfax.
}

John Contée Fairfax, eleventh Baron Fairfax, of Cameron, in the Scottish peerage, died recently at his residence, Northampton, Maryland. His name recalls the days of the great Civil War, but his family was famous even before that struggle. He was the descendant of Thomas Fairfax, knighted before Rouen in 1594, and raised to the peerage in 1627. The sixth baron settled in America, and was the friend of Washington. The deceased peer, who was born in 1830, and succeeded his brother, Charles Snowdon Fairfax, in 1869, devoted himself to the study of medicine. He was educated at the universities of Princeton and Pennsylvania; in the former he graduated in Arts, and in the latter he took the degree of M.D. He married a daughter of the late Colonel Kirby in 1857, and is succeeded by his elder son, Albert Kirby Fairfax.

\section{MEDICAL NEWS.}

\section{A Proposed Sanatorium for Consumptives of Moderate Means.}

THE movement for the suppression of consumption is now world wide, and "sanatorium" management has been proved to be, in every country and every climate, the most successful method of treatment. In Scotland there seems a likelihood of adequate provision being made for those who can afford to pay five or six guineas per week, and also for the very poor who are unable to pay anything. What is now wanted is an institution for those of moderate means of both sexes, who, by themselves or with the assistance of friends or Friendly Societies, can pay something like three guineas per week for three or four months' stay in a sanatorium in the early and most hopeful stages of the disease. The scheme should thus be essentially a philanthropic one, occupying a field which is as yet not covered by private enterprise or municipal effort; but it should not be a charitable institution, for those whom it would benefit are not in need of charity.

Seven thousand deaths are annually due to consumption, in Scotland. For the "sanatorium" treatment of these in the eight special sanatoria already-or about to be-erected, only 250 beds will be available. It is calculated that there are between 2000 and 3000 dying annually in Scotland who are able to afford a moderate rate of fees, but who at present are totally without effective means of cure.

In organising a consumptive sanatorium for those of moderate means, the following objects require to be kept in view:-(1) To provide an institution where everyone, on the first manifestation of consumption, can be admitted without undue delay. (2) By the erection of cheap yet efficient buildings, and by strict supervision and economy in administration, to reduce an estimated weekly charge of three guineas for those whose stay extends over three months, and whose special circumstances seem to require it. By such reductions many would be enabled to remain longer, and complete a successful cure. (3) To restore to health and to their work a limited number who can endure the stress of life, rather than to treat a large number whose disease, alleviated or arrested for the time being, can only result in a more prolonged illness. (4) With such a sanatorium in Scotland, patients who successfully undergo the system of treatment would be able to continue to live and work in their native country. 